تصميم الخريطة الأستثمارية ويناء قاعدة بيانات جغرافية للمشاريع الأستثمارية في محافظة بغداد

أ. د. مكي غازي عبد اللطيف المحمدي

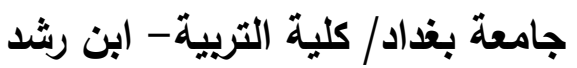

Makki19751975@gmail.com
م. م. م. وسن خزعل عبد العظيم السعدي

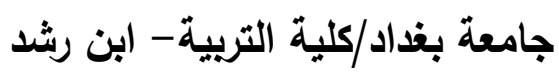
wasankhazal@gmail.com

\title{
(مُلَخَّصنُ البَحَث)
}

تتاول البحث مفهوم نظم المعلومات الجغرافية ومراحل بناء قاعدة البيانات الجغرافية

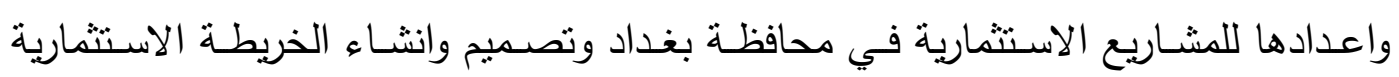

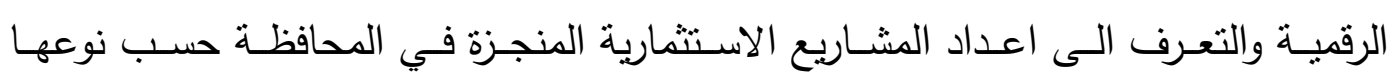

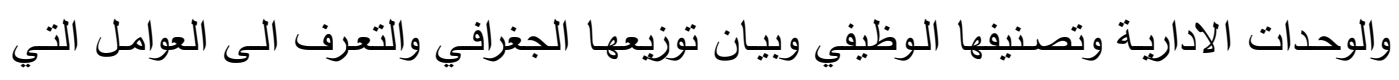

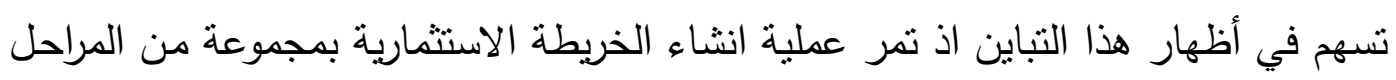

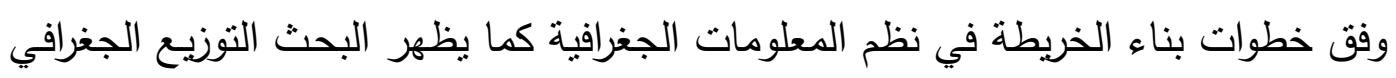
والقطاعي للمشاريع الاستثمارية في محافظة بغداد حسب مجموعة من المحددات التي تؤثر التر وتتاثر بأقامتها حسب موقعها الجغرافي. الكلمات المفتاحية : نظم المعلومات الجغرافية، قاعدة البيانات، الخريطة الرقمية، المشاريع المنجزة.

تصميم الخريطة الأستثمارية و بنـاء قاعدة بيانـات جغرافيـة للمشـاريع الأستثمارية في محافظة بغذاد

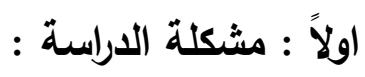

1. هل يمكن بناء قاعدة بيانات جغرافية للمشاريع الاستثمارية المنجزة في محافظة بغداد.

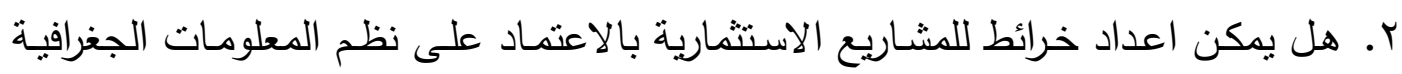

\section{ثانياً: : فرضية الدراسة :}

ا • يمكن بناء قاعدة بيانات جغرافية للمشاريع الاستثمارية المنجزة في محافظة بغداد

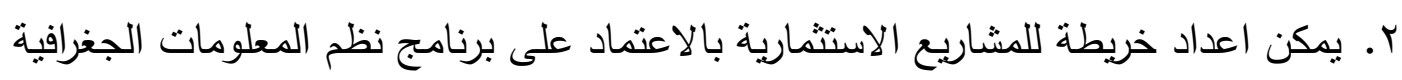

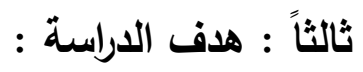
اعداد قاعدة بيانات جغرافية للمشاريع الاستثمارية المنجزة في محافظة بغداد

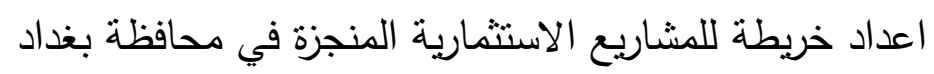




\section{تمهيد}

تعمل نظم المعلومـات الجغرافيـة على أنشـاء قاعدة بيانـات لكل ظـاهرة موجـودة على الخريطة كما وإن لها القدرة على التعامل مـع كم هائل من المعلومات لأي ظاهرة جغرافية وتتميز قواعد البيانات بأرتباطها بالتوقيع المكاني للبيانات والمعلومات الموجودة في الخريطة والمرئيات الفضائية وغيرها.

وقد توجهت الدراسة في هذا الفصل الى بيان مفهوم الخربطة الموضوعية والأستثمارية وبناء قاعدة البيانات جغرافيـة للمشـاريع الأستشمارية المنجزة والمخططة في محافظة بغداد لكافة القطاعات وأعداد خرائط لها بالأعتماد على خربطة الأسـاس من خلال البيانات التي تم جمعها من الدوائر ذات العلاقة. أولاً : نظم المعلومات الجغرافية وعلاقته بالاستثمار نظم المعلومات الجغرافية : تعد نظم المعلومات الجغرافية (Geographic Information System) من التقنيات الحديثة التي يمكن اسـتخدامها في تحديـد المواقع المناسبة لإقامـة أي منشـأة مـن خـله أستخدام الخرائط الرقمية وبأستخدام تطبيقات خاصة لمعالجة الكثير من المشاكل التي تواجه مختلف الخدمات من أجل تقديمها على أكمل وجه للسكان إذ تضم تقنية الـ GIS ثقنيات حديثة ذات قدرات منتوعة تستخدم في مجالات مختلفة ويشير مفهوم نظم المعلومات الجغرافية الى مجموعة النظم التي تقوم بتحليل البيانات ومعالجتها عن طريق إستخدام الحاسوب وذلك من خـلال ربط هذه المعلومات بمواقعها Layers الجغرافية وفق أحداثيات معينة وتتظيم المعلومات لتكون خرائط على شكل طبقات فئن

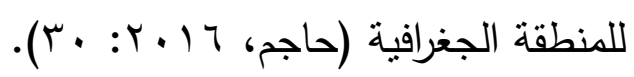
حيث تظهر أهميـة نظم المعلومـات الجغرافيـة مـن خـلال علاقتهـا بكثير مـن العلـوم ومجالات الحياة التطبيقية ومنها الأستثمار إذ تتجلى هذه الأهمية من خلال عدة نقاط هي: تحقيق تكامل للمشاريع الأستثارية .

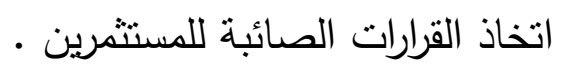
•إنتاج خرائط لتمثيل المشاريع الأستثمارية بقطاعاتها المختلفة . حيث تعـد نظم المعلومـات الجغرافيـة أداة علميـة ومهمـة مـن جانب حفظ المعلومـات

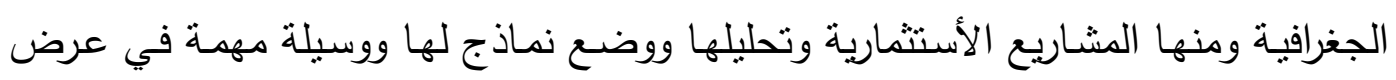
المشاريع على شكل خرائط جغرافية تساهم في توفير كافة المعلومات والبيانات. إذ إن أستخدام نظم المعلومات الجغرافية - GIS- في التخطيط للمشاريع الأستثمارية أصبح وسيلة مهمـة لتمكين أصـحاب القرار والمخططين من أتخاذ القرارات الصـائبة وفق 
الأحصائيات المتاحة وبالتالي التخطيط السليم مما يؤدي الى تحقيق التتمية ورفع معدلات النمو الأقتصـادي للبلد إذ تتبلور أهميـة ال GIS في الدراسـات التخطيطيـة من خلال جمـع البيانات وتوفيرها بأسلوب علمي وتوثيقها وفق برامج متخصصـة وربطها ببعض المتغيرات التي تؤثر في توزيعها الجغرافي وبالتالي التعرف على سلبيات وأيجابيات نوزيـع المشاريع الأسـتثمارية لتفـادي سـلبيات نمط التوزيـع الحـالي إذ تظهر العلاقـة بـين الأسـتمار ونظم المعلومات الجغرافية بتسهيل عملية رسم الخرائط بدقة عالية لمختلف المشـاريع الأستثمارية وتسـهيل حفظ البيانـات وسـهولة عمل نسـخ أحتياطي من الخرائط والبيانـات وتقليص الزمن المستغرق لتحليل المواقع والحصول على النتائج السريعة وعليه تظهر عدة أهداف توضـح إطـار العلاقـة بين نظم المعلومـات الجغرافيـة والأستثمار تظهر بشكل جلي في الدراسـات التخطيطية منتلة بأمكانية حفظ المعلومات بشكل واضتح وأستيعاب ومراقبة وتوفير البيانات الخاصــة بهـا وبنـاء نظـام أسـتثماري متكامـل يعتمـــ على تكنلوجيـا المعلومــات ومســاعدة

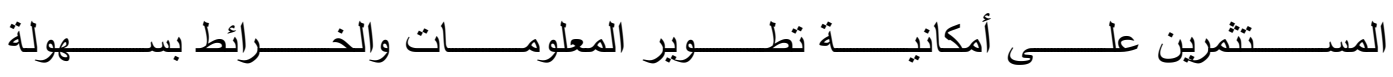
.(https://books.google.iq) أذ تتحدد العلاقة بين الأستثمار والمشـاريع الأستثمارية المقامـة في المحافظة مـع نظم

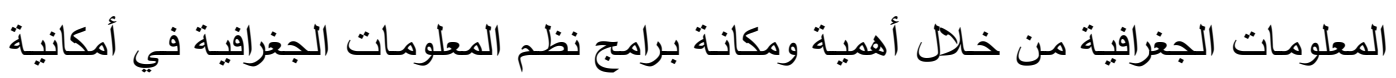
ربط أي مجموعة من البيانات للموقع الجغرافي مـع الأحداثيات المطلقة أو تلك التي يحددها

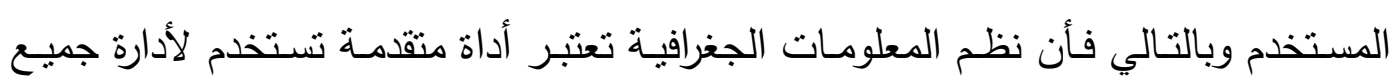
الأشكال والتحليلات المكانية.

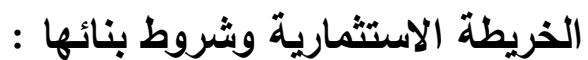

تتتـاول الدراسـة بشـكل رئيسـي المشـاريع الأسـتثمارية المكونـة للخربطــة الأسـتثمارية

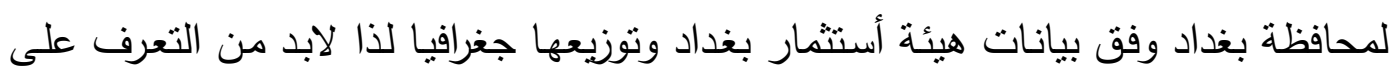
الخريطة الأستثمارية كمهوم وأهداف وأسس للألمام بالدراسـة من كافة الجوانب، والخريطة الموضـوعية تعتبـر أسـاس الخريطـة الأسـتثمارية لأنهـا نمثنل دراسـة موضـوع معـين وهـو الأستثمار إذ أن الخريطة الأستثمارية هي أحد أنواع الخرائط الموضوعية التي تمثل ظاهرة

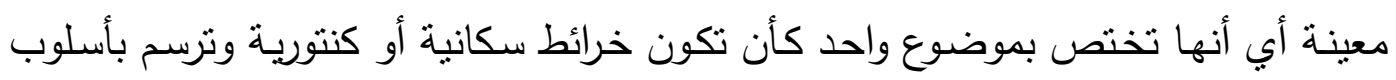

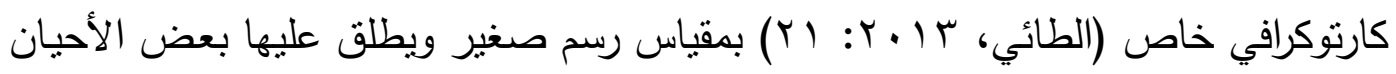

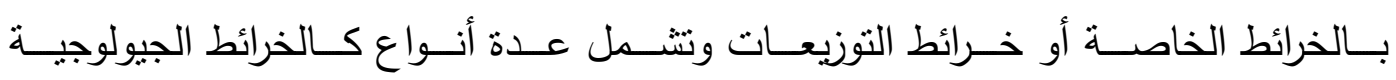
والجيمورفولوجيـة وأغلب فروع الجغرافيـة كخرائط الطقس والخرائط السياسية وغيرهـا وتعتبر هذه الخرائط ذات أهمية كبيرة من خلال رسمها وتحليلها التي تمكن الباحث في حل الكثير 


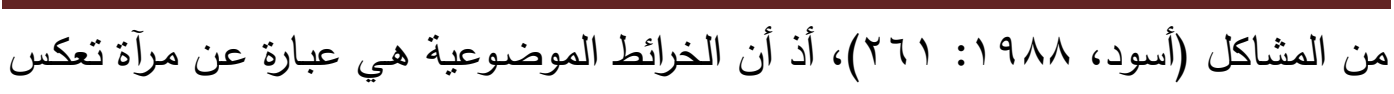

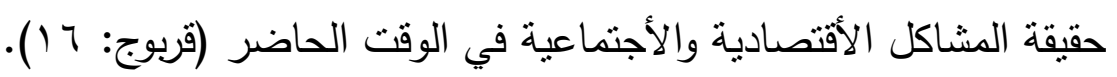
الخريطة الرقمية الاستثمارية (Map Digital Investors)

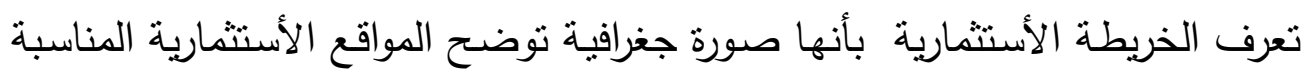

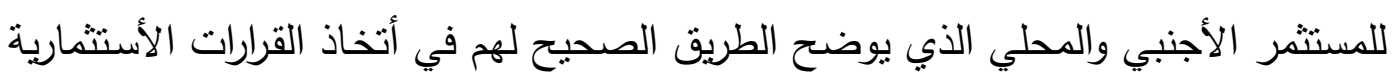

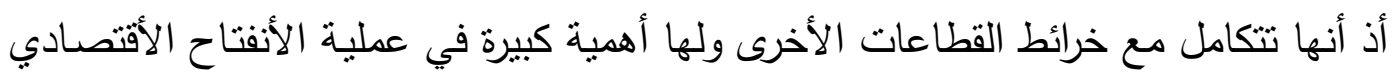

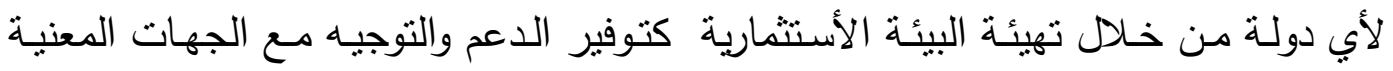

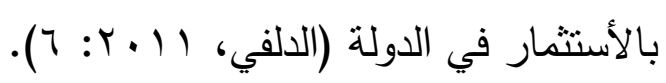
إذ أن الخريطة الأستثمارية تهدف الى زيادة وضوح أستثمارات الدولة المعنية و ينم فيها

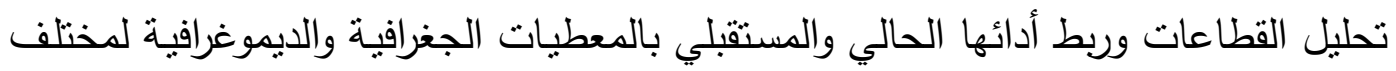
القطاعات كالقطاع السكني والصناعي والخدمي من خلال تحديد فرص الأستثمار في كل

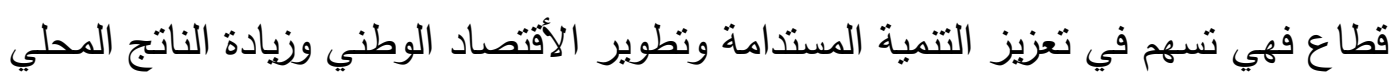
الأجمالي من خلال جذب الأستثمارات النوعية ونقل التكنلوجيا وتقليل الأعنماد على النفط

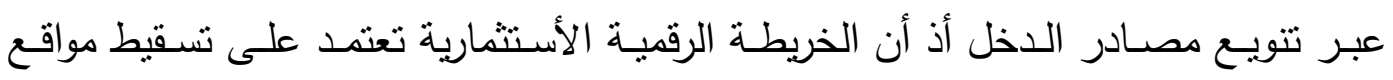

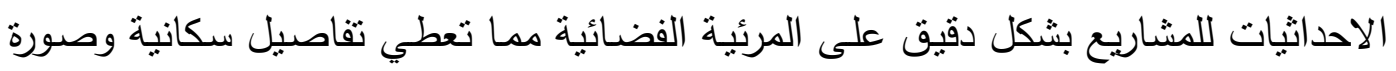
واضحة للمستثر حول العلاقات الترابطية للظواهر كما في علاقة السكان بالسوق والمواد

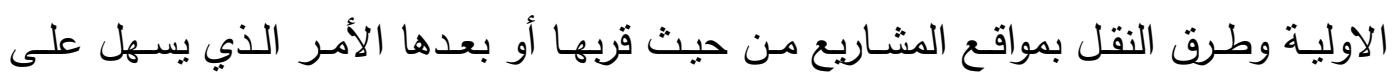
المستثمر أنخاذ القرارات المناسبة في دقة أختيار موقع المشروع.

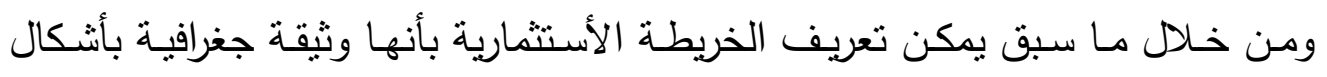

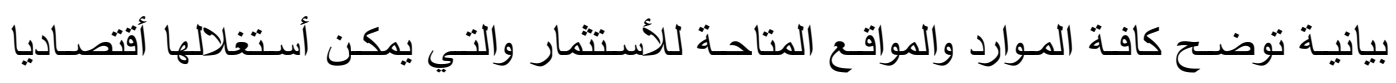

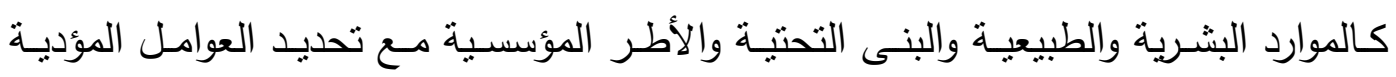

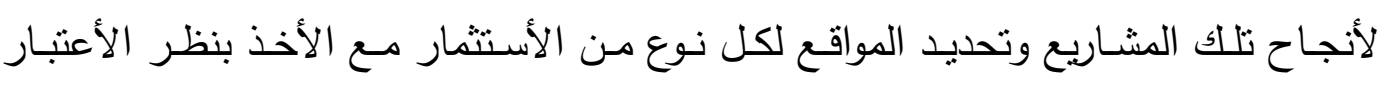

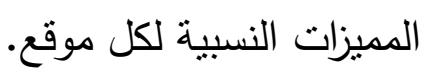
أسس بناء الخريطة الأستثمارية : يعد الموقع ومميزاته أحد العوامل المهئة في نجاح الخريطة الأستتمارية فهو يعطي

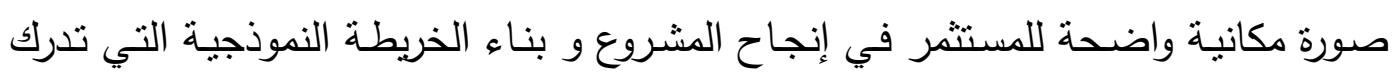

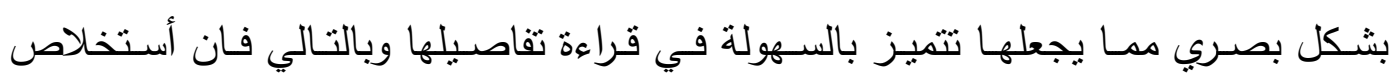

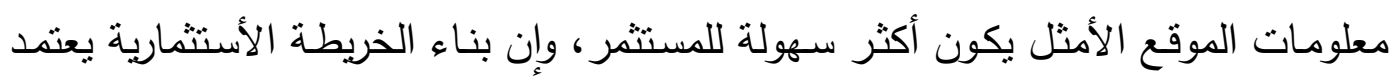

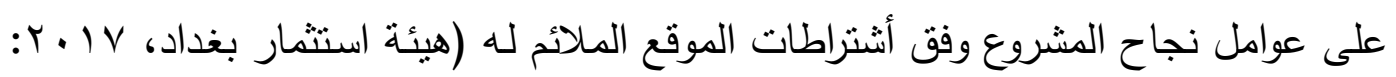


ويمكن أختصار عوامل نجاح بناء الخريطة الأستثمارية بما يأني:-

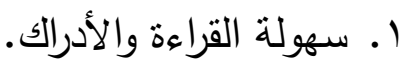
r. ( ب أختيار مقياس الرسم المناسب. r. أختيار الرموز الملائمة للظاهرة. ع. أختيار الوان ذات معاني ودلالات بصرية تعمل على أدراك الظاهرة. 0. أن تتضمن الخريطة تفاصيل مهمة تمنل طرق النقل والوحدات الادارية. أهداف الخريطة الأستثمارية : أخنطية

أن المشاريع التي تبنى على أساسها الخريطة الأستثمارية حقيقية ومستتدة الى البيانات والمعلومات الصحيحة بشكل يعتمد على وجود بيئة مناسبة لأقامة المشاريع المقترحة لإعلى الإداد

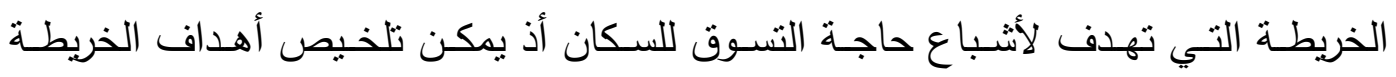

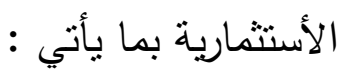
1 - توفير البيانات والمعلومات للمستثمرين لمساعدتهم في أتخاذ قرار أستثماري سليم.

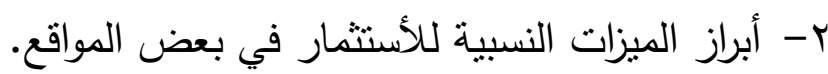
r- وضع موجهات للأستتمار تتسق مع أستراتيجيات وخطط وسياسات التتمية الأقتصادية والأجتماعية.

ع - تحديد مجالات الأستثمار الحالية والمستقبيلة.

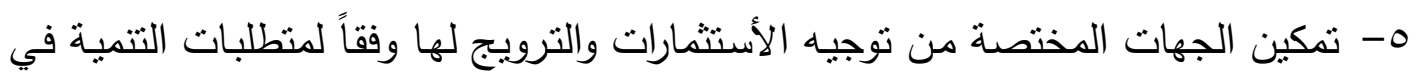

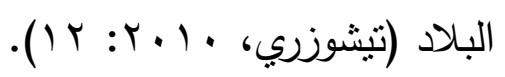

\section{قاعدة البيانات الجغرافية للمشاريع الأستثمارية في محافظة بغداد : البناد :}

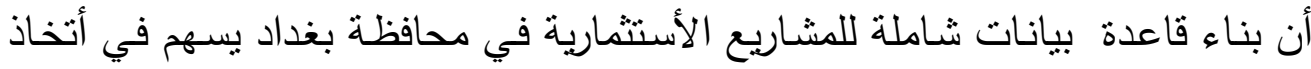

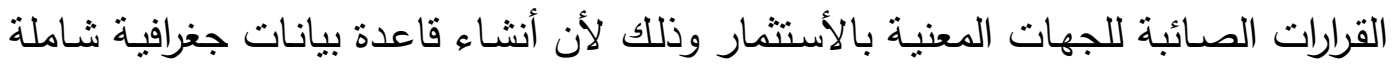

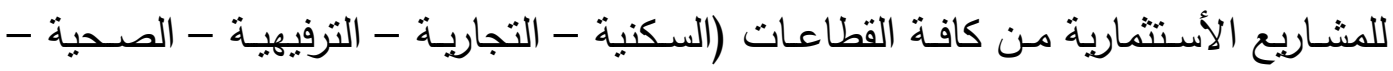
التعليمية - الصناعية - الزراعية) يساعد في أنشاء خطط عالية الدقة قصيرة وبعيدة المدى. تعد قاعدة البيانات الجغرافية مجموعة من ملفات تضم معلومات مرموزة وفق أحداثيات

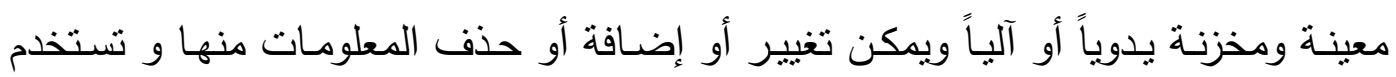

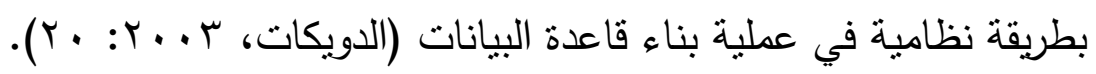

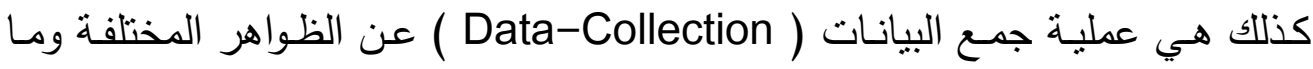

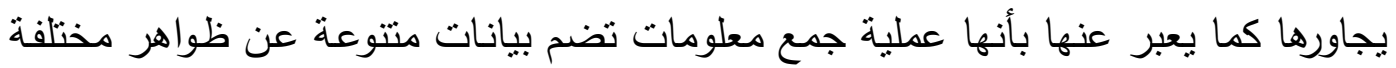

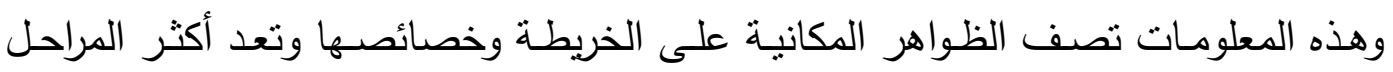




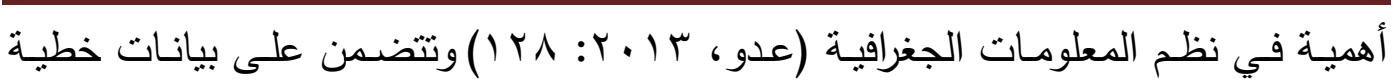
ونقطية.

ومن أجل بناء نظام معلومات جغرافية لمنطقة معينة لابد من تصميم قاعدة بيانات

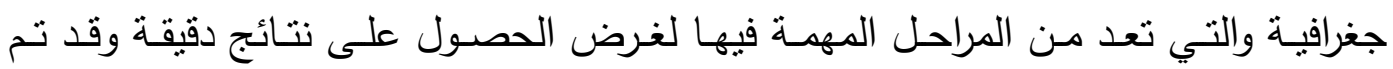

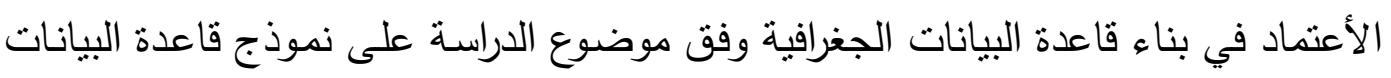

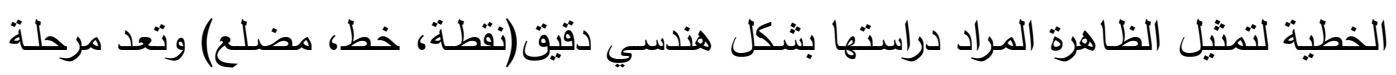

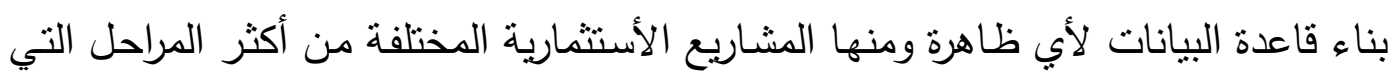
تتطلب وقت وجها إلا أنها ذات فوائد عديدة منها: سهولة أستخدام البيانات في برمجيات مختلفة. سرعة الوصول الى البيانات. سهولة تداول المعلومات بين الأثخاص والمؤسسات. • تقلل الخطأ في نقل البيانات من خلاد الأعتماد على الأحداثيات الاقيقة. توحيد طرق القياس والتخزين والتحديث للبيانات.

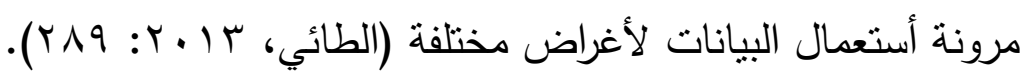
وتتسم قاعدة البيانات الجغرافية بأعتمادها على نوعين أساسيين للبيانات هما:أولاً: البيانات المكانية Spatial data

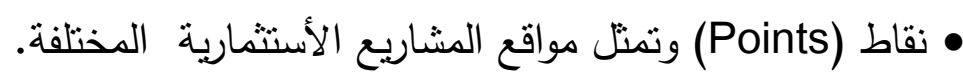

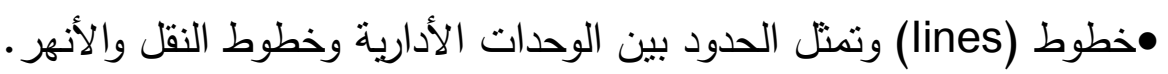

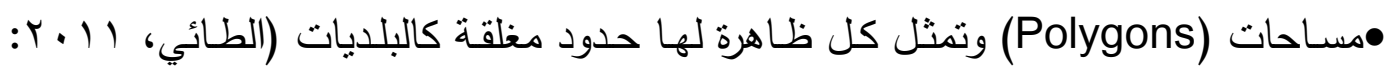

ثانياً : البيانات الوصفية Attrepute data

وهي نلك البيانات الكتابية التي تتسب الى المعلومات المكانية وتكون في صور وقوائم

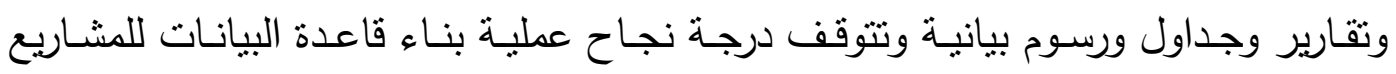

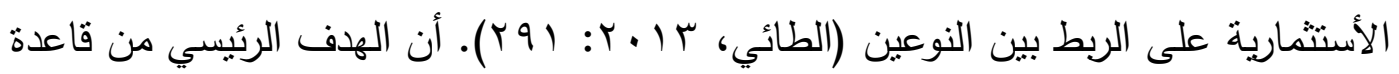

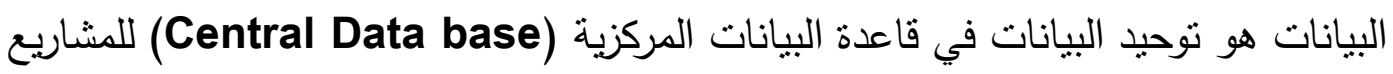
الأستثمارية التي تتبناها هيئة أستثمار بغداد وتثقم الى القطاعات الرئيسية حسب الوحدات

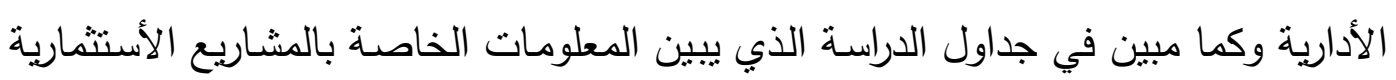

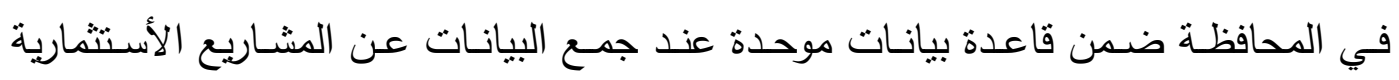

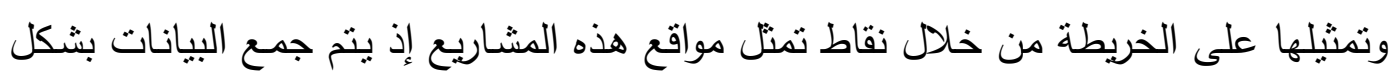

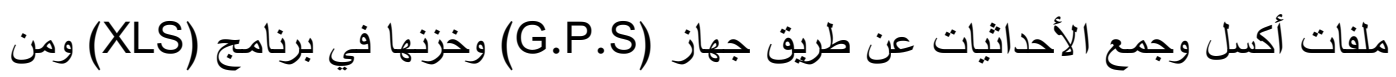


Arc لكم تحويل ملفات البيانات الى Data Base لكي التعامل مع الملف في برنامج GIS وتحويلها الى Shap file ثم الى Feature class (سليمان، 10 • ب: V V). مخطط (1) المكونات الأساسية لقاعدة البيانات الجغرافية لمحافظة بغداد

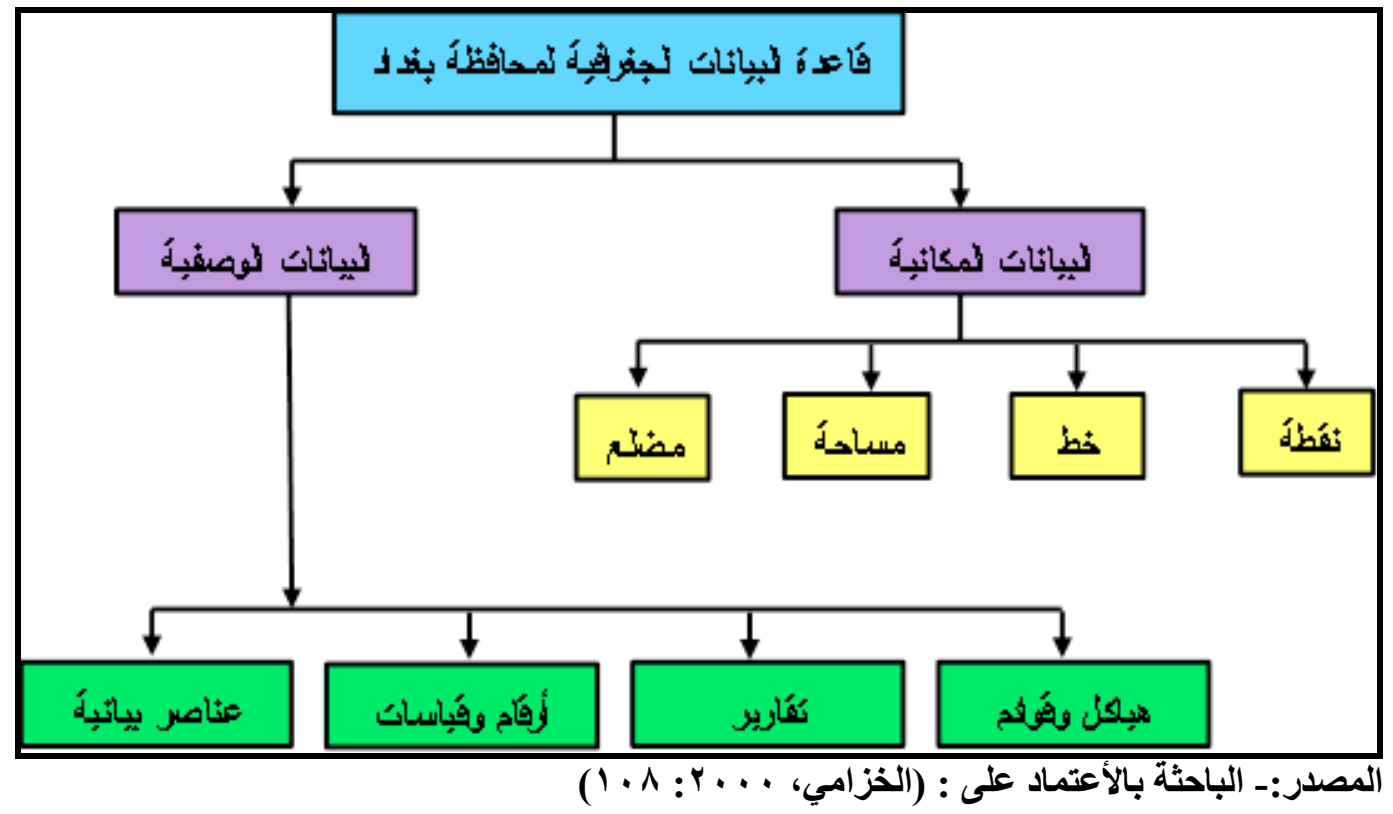

ثانيـاً: مراحلـل بنـاء قاعـدة البياتـات الجغرافيـة لخــائط المشــاريع الأسـتثمارية المنجـزة والمخططة في محافظة بغداد:

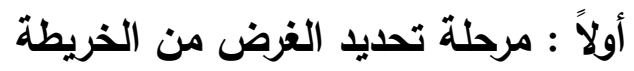

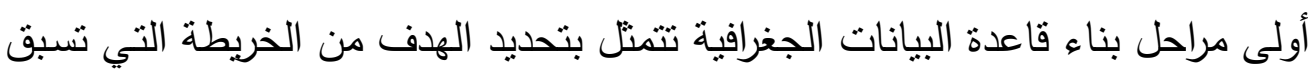

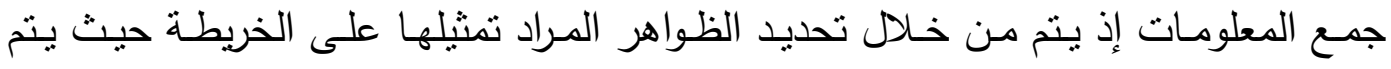
أختيار البرنامج المناسب للرسم مع أختيار المسقط والمقياس وأبعاد الخريطة المناسبة للرسم

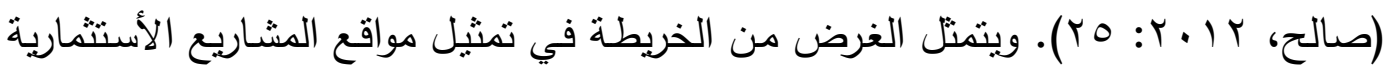
برموز التمثيل الكارتوكرافي المختلفة لمعرفة مواقعها وكيفية الوصول إليها. ثانياً : مرحلة تحديد محافظة بغداد ومساحتها

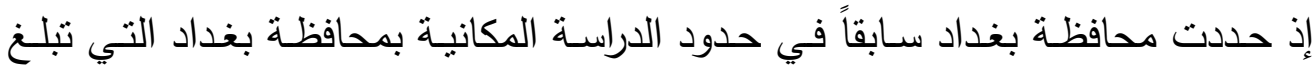

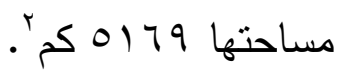

ثالثاً: مرحلة جمع البيانات الاساسية للخرائط وإدخالها يتم جمع البيانات من مصادرها المختلفة ثم يتم تتصنيفها الى بيانات وصفية ومكانية

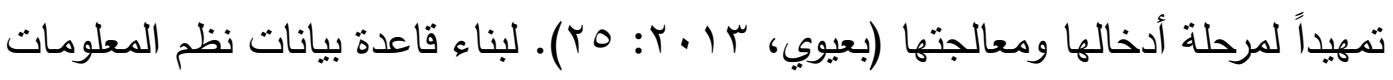

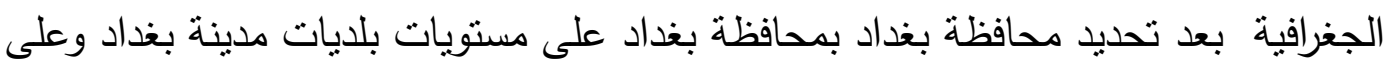

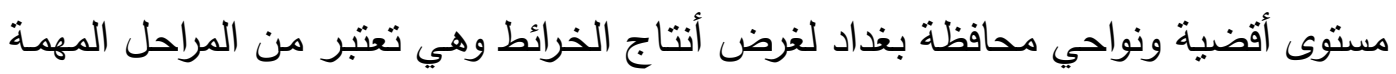
وهناك عدة طرق لأدخال البيانات وهذا يعتمد على نوع الخريطة والغرض منها لغنا (الزيدي، 


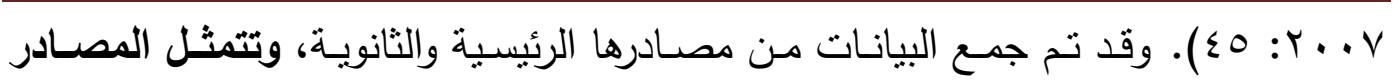

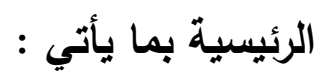
- البيانات الأحصائية التي تعدها الدوائر ذات العلاقة.

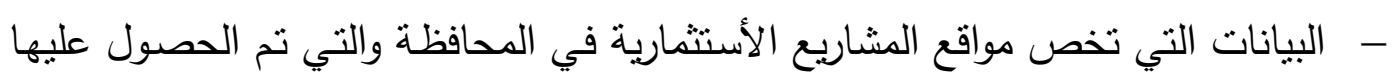
من مصادرها المختلفة منها ومنها : 1 - أمانة بغداد، قسم التصاميم GIS ، قسم الأستثمار ، قسم التخطيط الحضري.

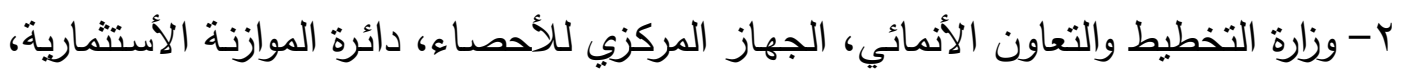
دائرة التتمية البشرية.

r- محافظة بغداد، قسم النافذة، هيئة أستثمار بغداد، قسم التخطيط الحضري.

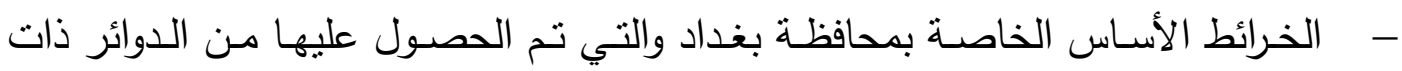

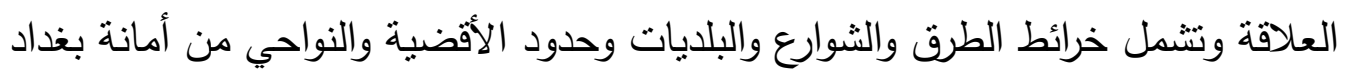

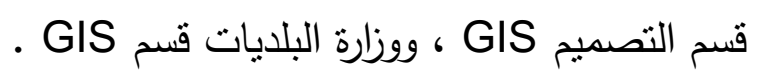

- المرئية الفضائية التي تم ذكر مواصفاتها في الفصل الاول ضمن مراحل عمل الدراسة.

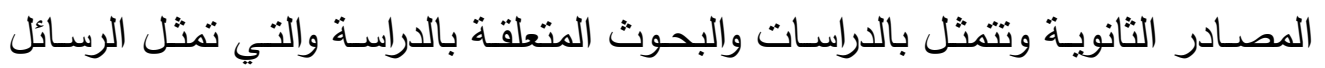

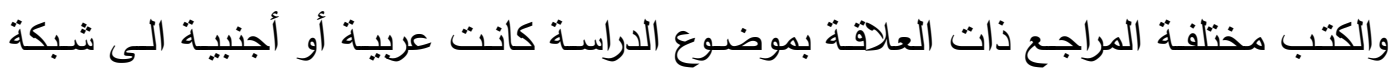
الأنترنيت الدولية وأن أتمام عملية بناء قاعدة البيانات الجغرافية تكمن في وجود : - المنطلبات المادية (مكونات الحاسوب الآلي). - المنطلبات البشرية (الكادر المختص في أستعمال تقنية الحاسوب).

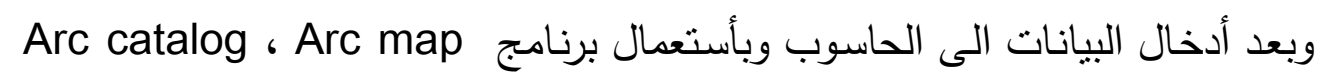

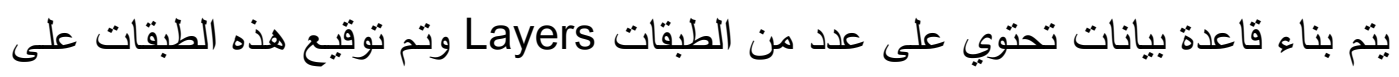
خريطة الأساس تمهيداً لرسم الخريطة الأستثمارية حسب خلثي خرائط مواقع المشاريع الأستثمارية ينظر جدول (1). (1) - (1)

جدول (1) الطبقات التي تم أستخدامها لتصميم الخريطة الأستثمارية

\begin{tabular}{|c|c|c|c|}
\hline Layers Line & Layers Polygon & Layers Point & $ت$ \\
\hline الشوارع & الأقضية و النواحي والبلديات & مشاريع سكنية & $\overline{11}$ \\
\hline الأنهر & البلايات & مشاريع تجارية & 2 \\
\hline \multirow[t]{5}{*}{ الحدود } & الأقضية و النواحي والبلايات & مشاريع ترفيهية & 3 \\
\hline & البلديات & مشاريع تعليمية & 4 \\
\hline & 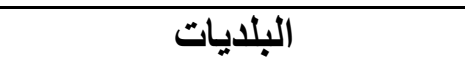 & مشاريع صحية & 5 \\
\hline & الأقضية و النواحي & مشاريع صناعية & 6 \\
\hline & الأقضية و النواحي & مشاريع زراعية & 7 \\
\hline
\end{tabular}

الصصدر: الباحثة بالأعتماد على برنامج 10.4 Arc GIS 
رابعاً : مرحلة تحديد المسقط المستخدم الذي يلائم الغرض من الخريطة ومقياسها

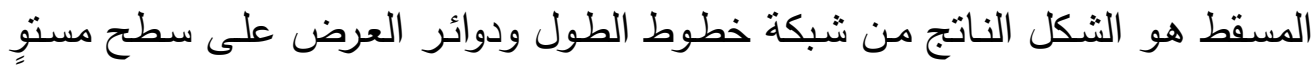

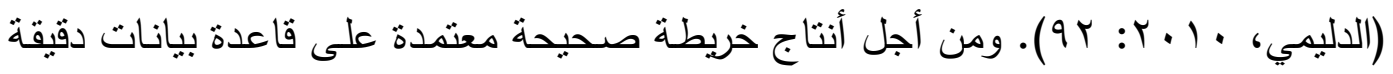

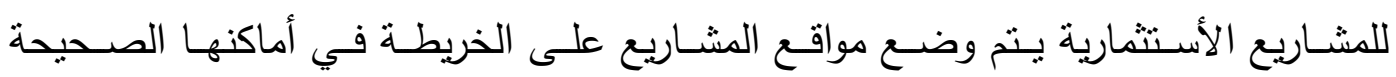

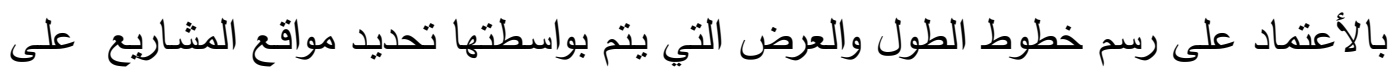

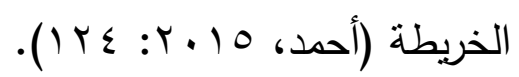

ويتم أعتماد مسقط ميركانور المستعرض UTM لمحافظة بغداد والنظام العالمي الخاص

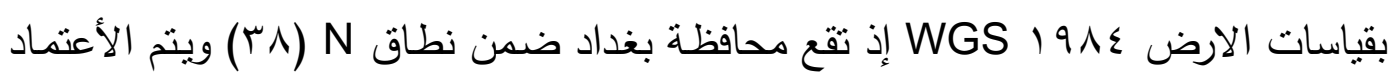

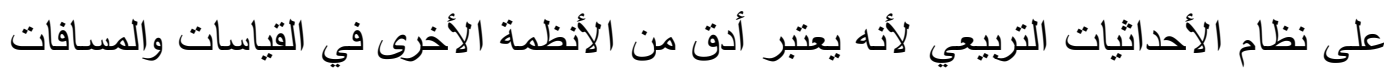

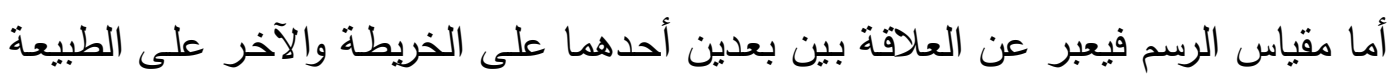

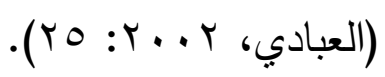

خامساً: مرحلة معالجة البيانات ورسم الخرائط

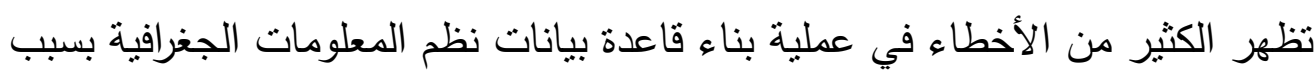
أدخال المعلومات أكثر من مرة أو بسبب وجود أخطاء في البيانات مثل عدم دقة الأحداثيات

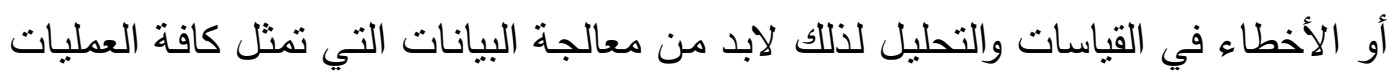
التي يمكن من خلالها أدارة قاعدة المعلومات بهدف الحصول على فائدة معينة وتتتم عملية

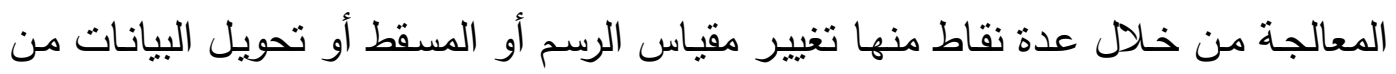

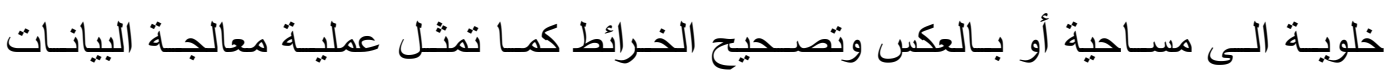

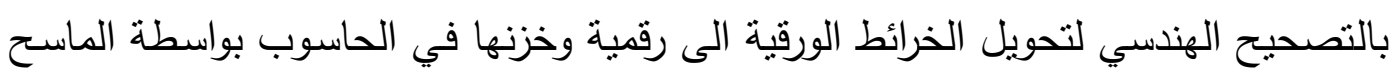

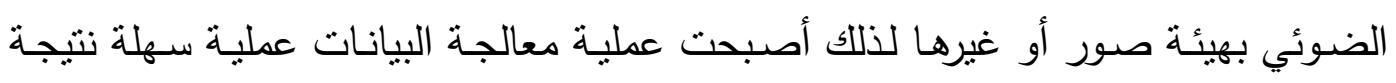

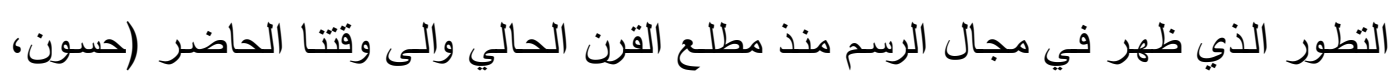

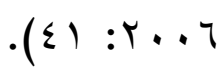

سادساً: مرحلة الإخراج وإنتاج الخرائط

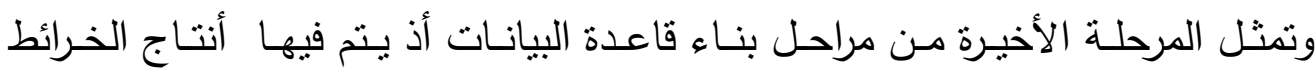
الخاصـة بالدراسة بصورتها النهائية بعد أضـافة منطلبات الرسم للأخراج النهائي كالأطسار

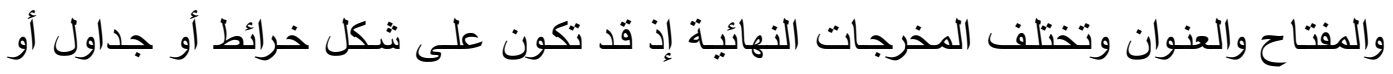

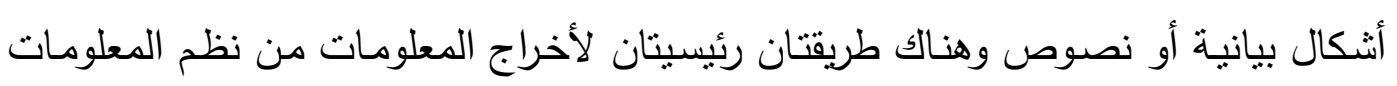

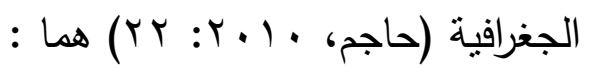

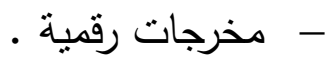

$$
\begin{aligned}
& \text { - مخرجات مطبوعة. }
\end{aligned}
$$


وقد تم تلخيص هذه المراحل في مخطط يوضتح خطوات بناء قاعدة البيانات للمشاريع

الاستثمارية في محافظة بغداد بنظر مخطط (Y).

\section{مخطط (Y) المخطط الهيكلي لنظم بناء قاعدة البيانات}

للمشاريع الأسنثمارية في محافظة بغداد

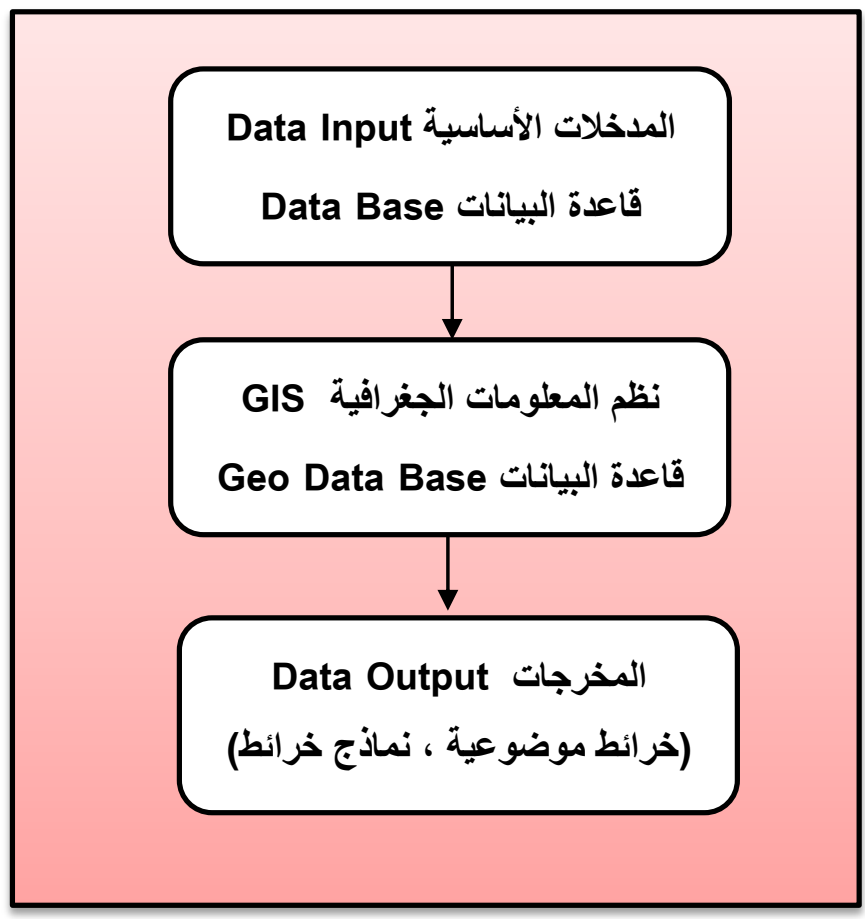

المصدر:- الباحثة

المشاريع الأستثمارية المنجزة في محافظة بغداد حسب الوحدات الإدارية :

أن لمعرفة مدى التباين بين الوحدات الادارية لمحافظة بغداد للمشاريع الأستثمارية وأي لئي المشاريع أكثر أنتشاراً من المشاريع الأخرى أهمية كبيرة ذلك لأن كل نوع من تلك المشاريع أهمية تختلف عن المشاريع الأخرى وقد تم بناء جدول(10) الذي يوضـح التوزيع المتباين للمشاريع الأستثمارية بين الوحدات الإدارية بمختلف قطاعاتها حسب الأقضية والنواحي إذ تم دراسـة المشـاريع الأستثمارية في محافظة بغداد على مستوى البلديات التابعة لمدينـة بغداد على حدة والتي بلغـت أعدادها (123) مشـروع وعلى مسـتوى الأقضـية والنـواحي التابعـة لمحافظـة بغداد خـارج الحدود الاداريـة لمدينـة بغداد على حدة و بلغت (48) مشـروع أي بمجموع (171) مشروع على مستوى المحافظة ككل ويرجع سبب زبادة عدد المشاريع في المدينة عما هو في المحافظة الى التركز السكاني والمؤسسي فيها بشكل يفوق عما هو عليه في خارج حدودها الأدارية إذ نجد أنه بالرغم من وجود مساحات كبيرة خالية وجاهزة لأقامة مختلف المشاريع الأستشمارية خارج الحدود الأدارية لمدينة بغداد إلا إن العامل السكاني هو العامل الأبرز في التأثير على إقامة هذه المشاريع فيها مع العوامل الأخرى كخدمات البنية 
جدول (r) المشاريع الأستثمارية المنجزة في محافظة بغداد حسب الأقضية والنواحي التي

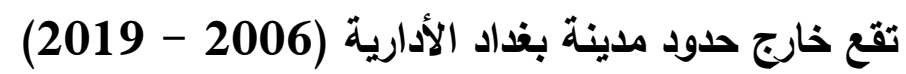

\begin{tabular}{|c|c|c|c|}
\hline$\%$ & عدد المشاريع & الوحدات الأدارية & القضاء \\
\hline & & مركز قضاء الرصافة & \multirow{4}{*}{ قضاء الرصافة } \\
\hline & & ناحية الكرادة & \\
\hline & & ناحية بغداد الجديدة & \\
\hline & & ناحية فلسطين & \\
\hline & & مركز قضاء الأعظمية & \multirow{4}{*}{ قضاء الأعظمية } \\
\hline & & ناحية الراشدية & \\
\hline$r$ & 1 & ناحية الزهور & \\
\hline & & ناحية الفحامة & \\
\hline & & مركز قضاء الصدر الثانية & \multirow{3}{*}{ قضاء الصدر الثانية } \\
\hline & & ناحية ابناء الرافدين & \\
\hline & & ناحية المنورة & \\
\hline & & مركز قضاء الصدر الثانية & \multirow{3}{*}{ قضاء الصدر الأولى } \\
\hline & & ناحية الصديق الأكبر & \\
\hline & & ناحية الفرات & \\
\hline $1 \leqslant, 0$ & $\mathrm{v}$ & مركز قضاء المدائن & \multirow{3}{*}{ قضاء المدائن } \\
\hline $1 \cdot, \varepsilon$ & 0 & ناحية الجسر & \\
\hline 19 & 9 & ناحية الوحلة & \\
\hline & rr & مركز قضاء الكاظمية & \multirow{3}{*}{ قضاء الكاظمية } \\
\hline r & 1 & ناحية التاجي & \\
\hline & & ناحية ذات السلاسل & \\
\hline IV & $\Lambda$ & مركز قضاء المحمودية & \multirow{4}{*}{ قضاء المحمودية } \\
\hline$\varepsilon$ & $\bar{r}$ & ناحية اليوسفية & \\
\hline$\Lambda$ & $\xi$ & ناحية اللطيفية & \\
\hline$\Lambda, r$ & $\varepsilon$ & ناحية الرشيا & \\
\hline$\Lambda, r$ & $\varepsilon$ & مركز قضاء ابو غريب & \multirow{2}{*}{ قضاء ابو غريب } \\
\hline$\varepsilon$ & $r$ & ناحية النصرو السلام & \\
\hline & & مركز قضاء الطارمية & \multirow{3}{*}{ قضاء الطارمية } \\
\hline$Y, 0$ & 1 & ناحية المشاهدة & \\
\hline & & ناحية العبايجي & \\
\hline & & مركز قضاء الكرخ & \multirow{3}{*}{ قضاءالكرخ } \\
\hline & & ناحية المنصور & \\
\hline & & ناحية المأمون & \\
\hline $1 \ldots$ & $\varepsilon \wedge$ & \multicolumn{2}{|c|}{ المجموع } \\
\hline
\end{tabular}

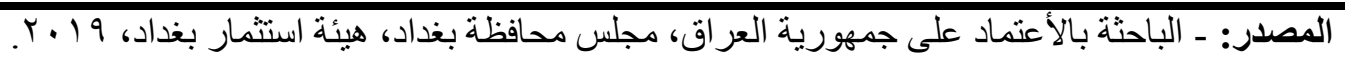


وبالنظر إلى جدول (Y) نجد أن كل من ناحية الوحدة ومركز قضاء المحمودية والمدائن

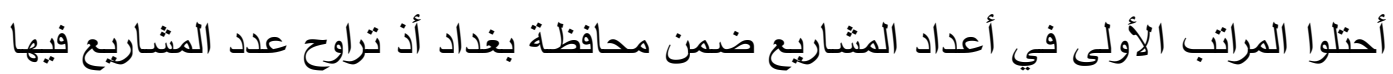

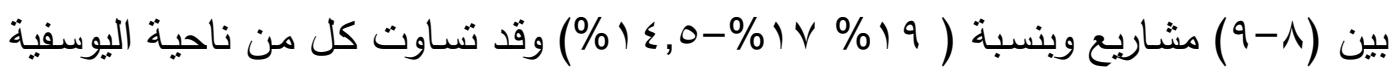
والنصر والسلام في عدد المشاريع بواقع (2) مشروع وبنسبة (4\%) لكل منها وأقل نسبة سجلت في ناحية المشاهدة (Y,0\%) بسبب بعدها عن المركز ورداءة خدمات البنى التحتية

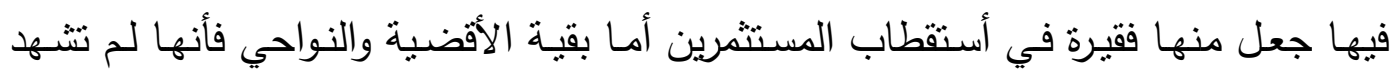

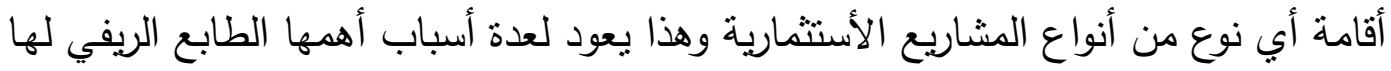

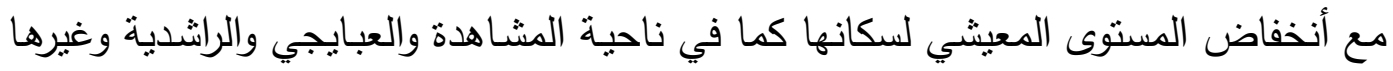

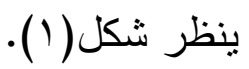
شكل (1) التوزيع النسبي للمشاريع الأستثمارية المنجزة في محافظة بغداد حسب الأقضية

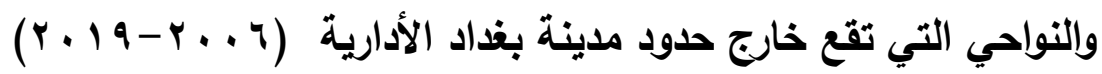

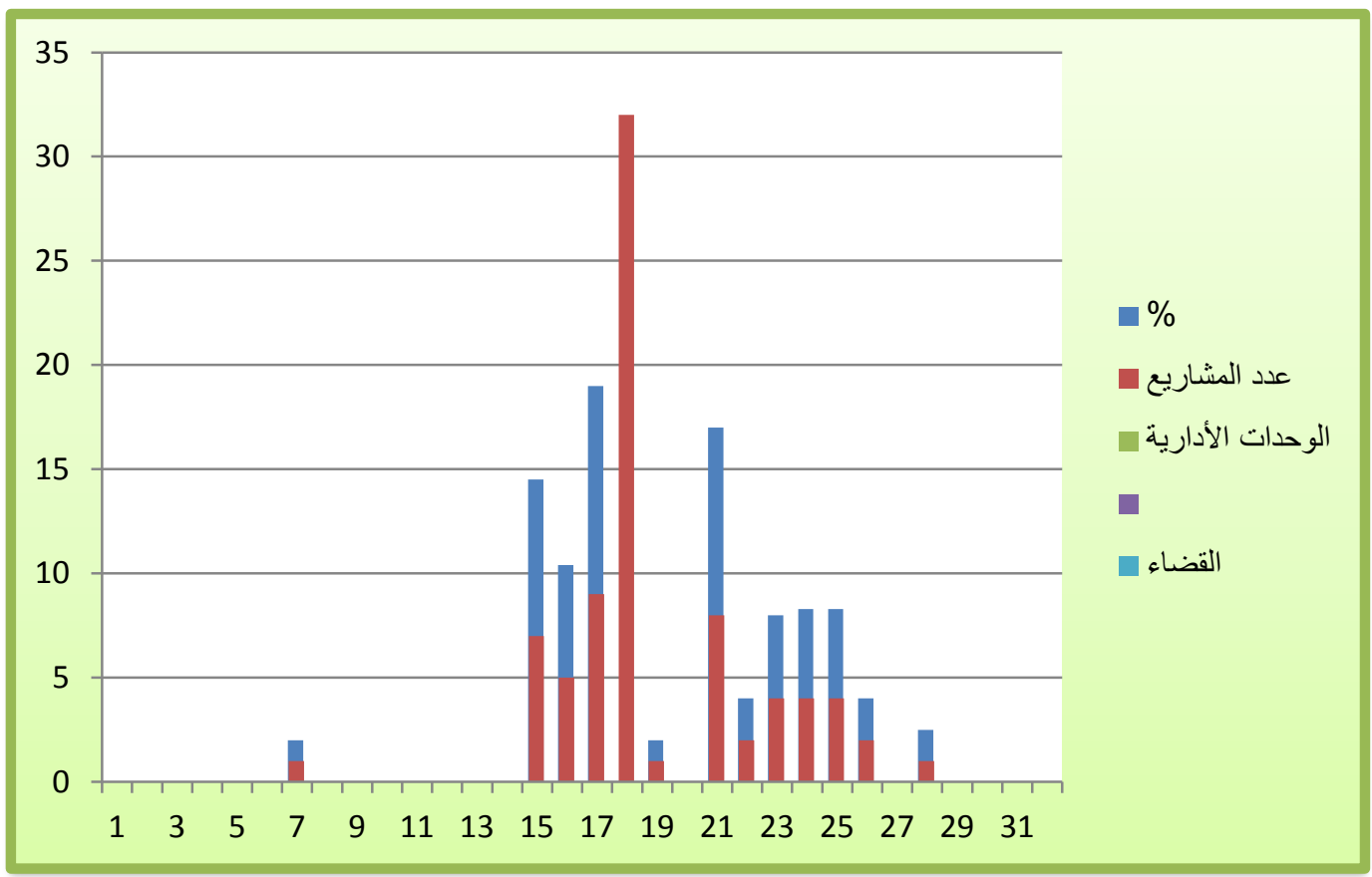

المصدر: الباحثة بالأعتماد على جدول (ץ) 
خريطة (1) المشاريع الأستثمارية المنجزة في محافظة بذاد حسب الأقضية والنواحي

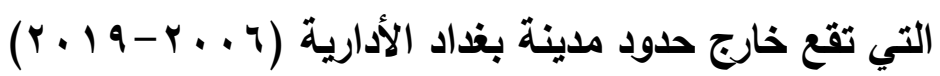

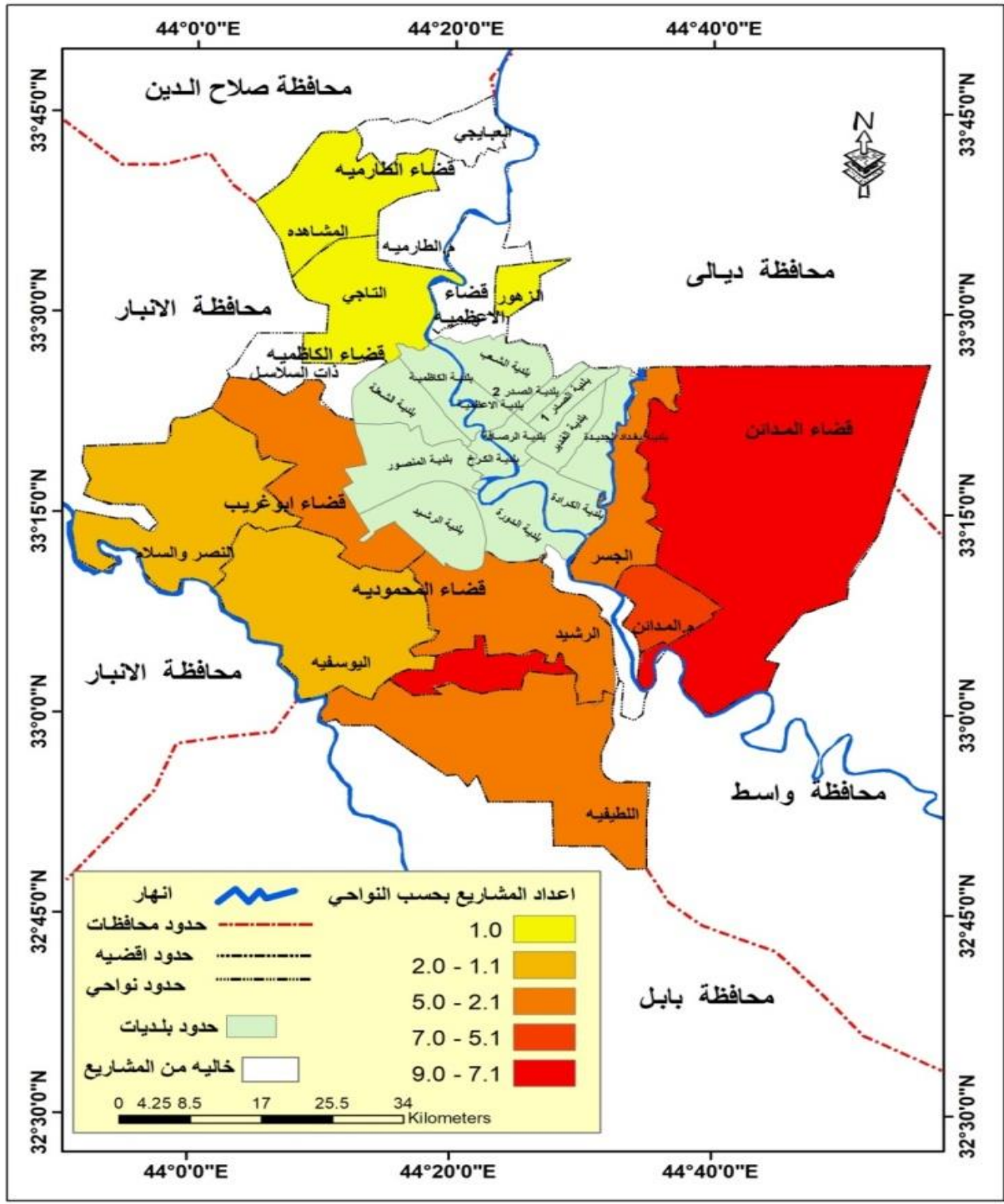

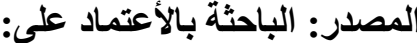

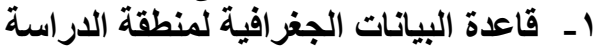

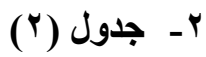

وبالنظر الى جدول (r) يتضح أن كل من بلدية المنصور والكرادة والكاظمية والغدير

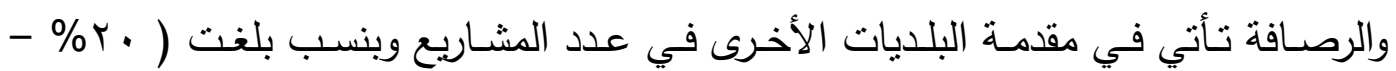

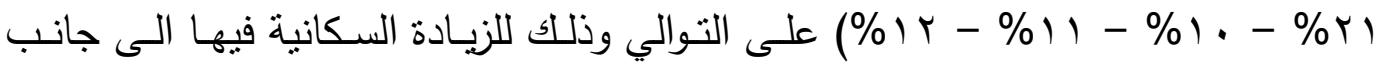
حاجتها لمختلف المشاريع مع أرتفاع المستوى المعيشي لمعظم سكانها مما دفع المستثمرين

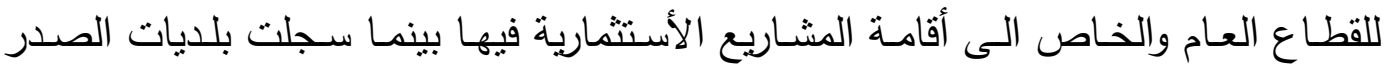

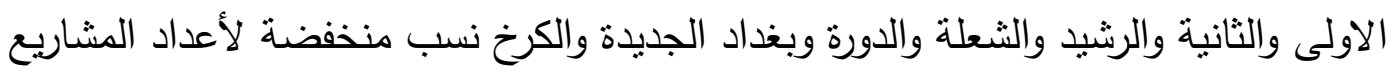

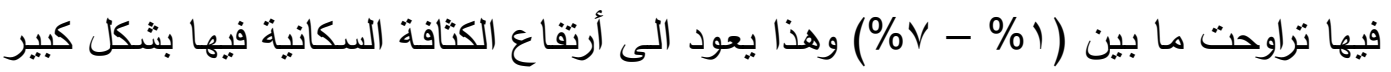




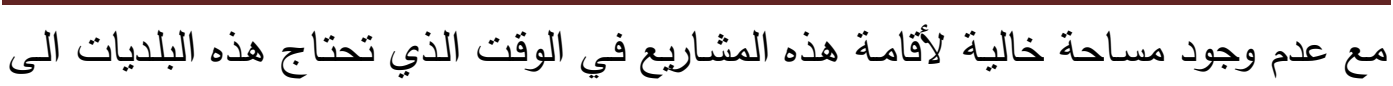

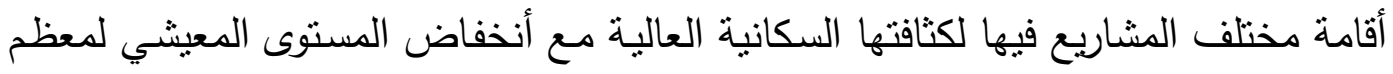

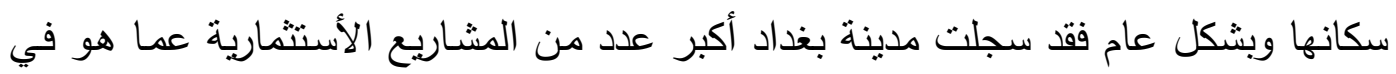

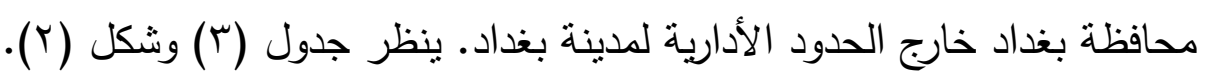

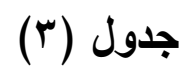

المشاريع الأستثمارية المنجزة في مدينة بغداد حسب البلديات (2006 - 2019)

\begin{tabular}{|c|c|c|c|}
\hline$\%$ & عدد المشاريع & الوحدات الادارية & $ت$ \\
\hline 12 & $\overline{15}$ & بلاية الرصافة & 1 \\
\hline 7 & 8 & بلاية الكرخ & 2 \\
\hline 5 & 6 & بلاية الأعظمية & 3 \\
\hline 10 & 12 & بلاية الكاظمية & 4 \\
\hline 3 & 4 & بلدية الثعب & 5 \\
\hline 1 & 1 & بلاية الصدر الأولى & 6 \\
\hline 1 & 1 & بلاية الصدر الثانية & 7 \\
\hline 2.4 & 3 & بلاية الرشيا & 8 \\
\hline 11 & 14 & بلاية الغذير & 9 \\
\hline 2.4 & 3 & بلدية بغداد الجديدة & 10 \\
\hline 20 & 24 & بلدية المنصور & 11 \\
\hline 21 & 26 & بلاية الكرادة & 12 \\
\hline 2.4 & 3 & بلدية الشعلة & 13 \\
\hline 2 & 2 & بلاية الدورة & 14 \\
\hline 100 & 123 & المجموع & \\
\hline
\end{tabular}

المصدر: الباحثة بالأعتماد على ملحق (1)

شكل (r) التوزيع النسبي للمشاريع الأستثمارية المنجزة في مدينة بذداد حسب البلايات

$(r \cdot 19-r+\urcorner$.

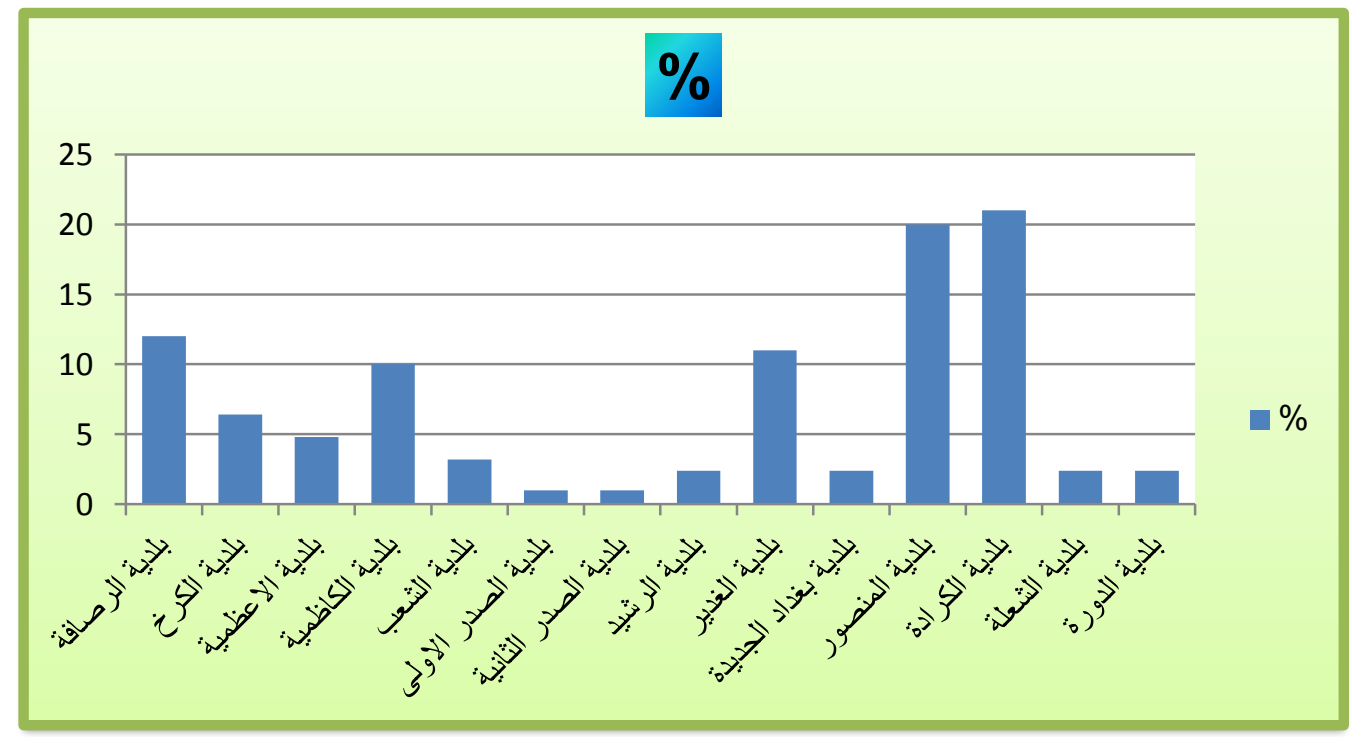

المصدر: الباحثة بالأعتماد على جدول (ॅ) 
خريطة (r)

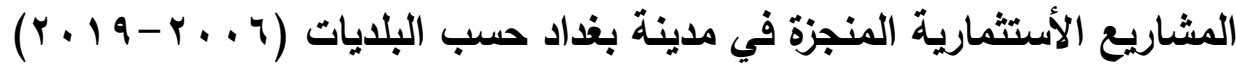

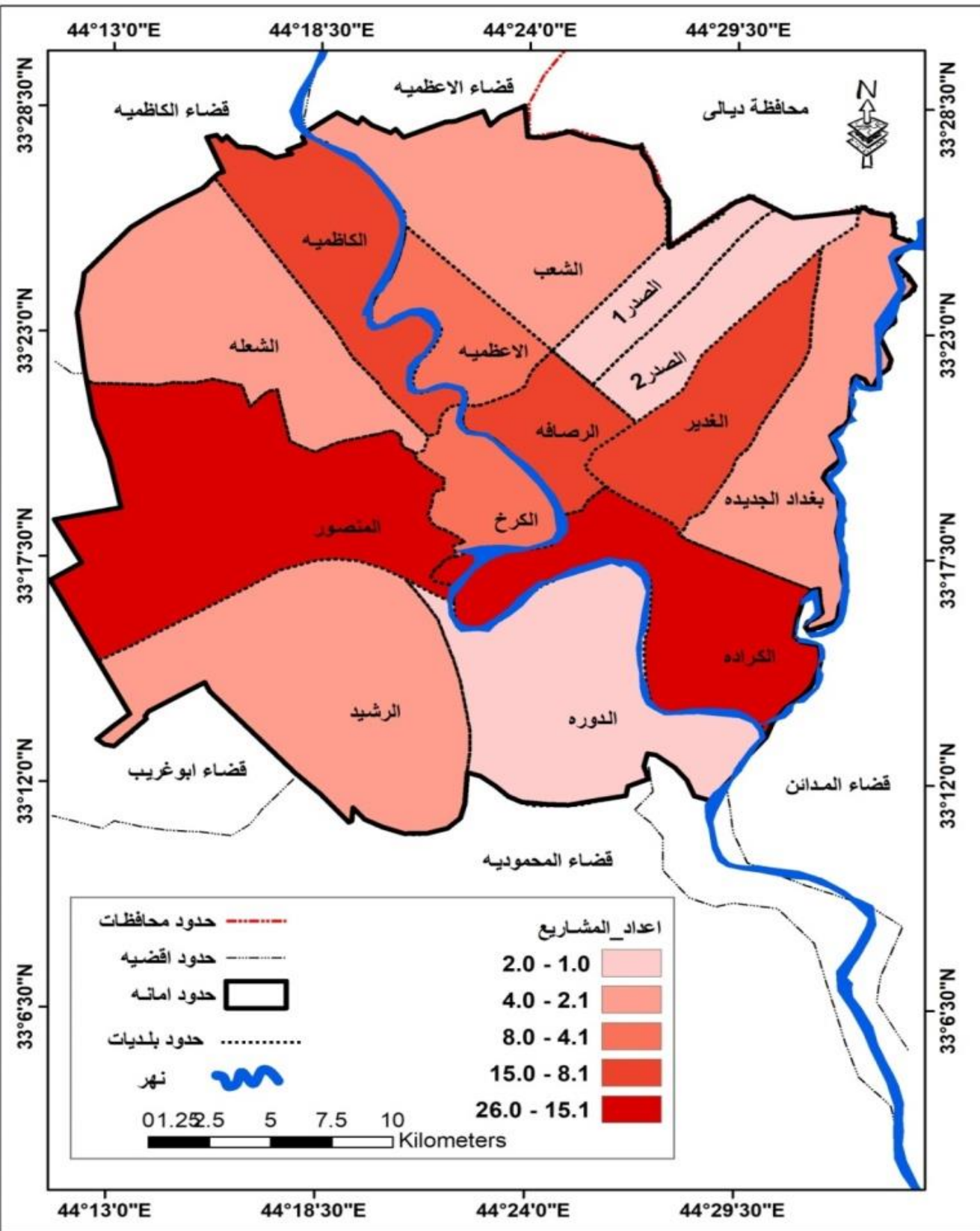

المصدر: الباحثة بالأعتماد على

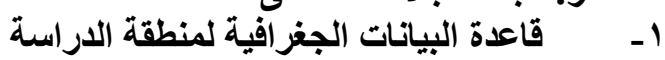

(r) 


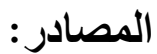

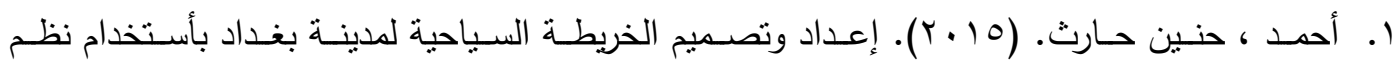
المعلومات الجغرافية GIS، رسالة ماجستير ، جامعة بغداد.

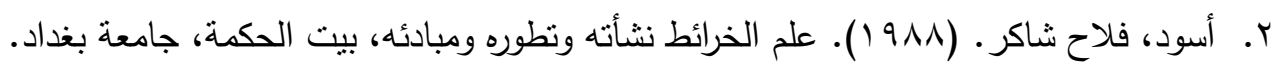

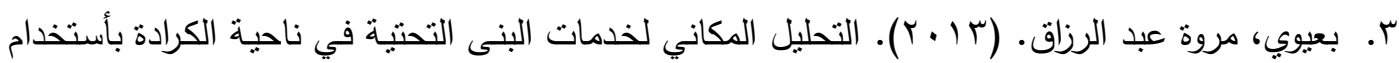
نظم المعلومات الجغرافية GIS ، رسالة ماجستبر ، جامعة بغداد.

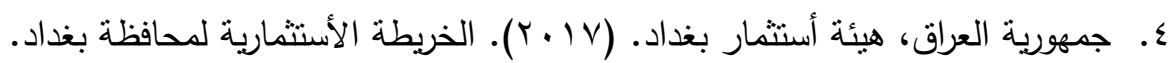

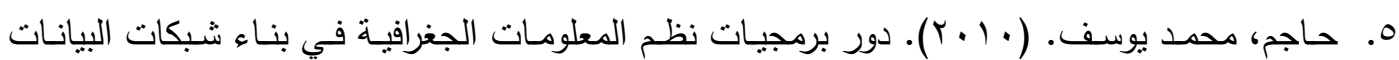

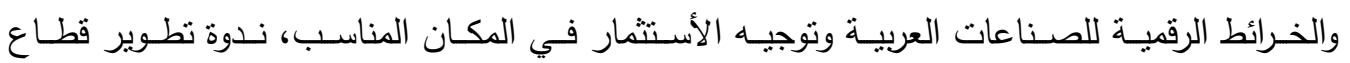
المعلومات الصناعية في الدول العربية، بيروت.

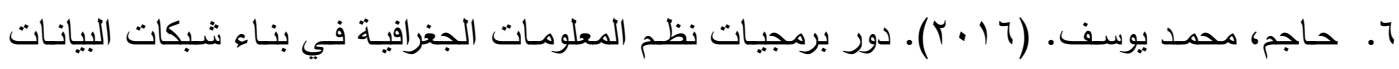

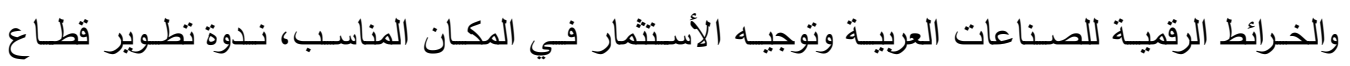
المعلومات الصناعية في الدول العربية ، بيروت.

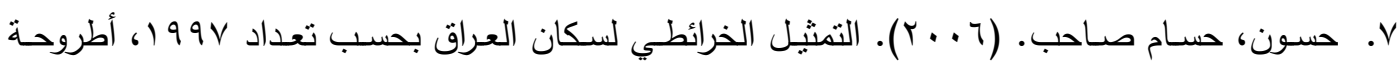

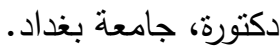

^. الخزامي، محمد عزيز • ( . . ب). نظم المعلومات الجغرافية أسسها وتطبيقها للجغرافيين، ط؟، منشـأة المعرفة، الاسكندرية.

9. الدلفي، حيدر عبد راضي. (11 • ( ). البيئة الأستثمارية وسبل الأرنقاء بها في العراق (محافظة واسط

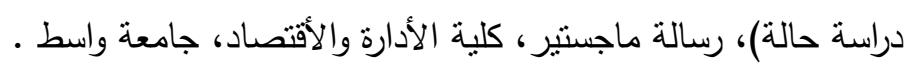

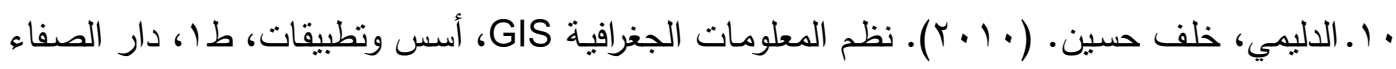

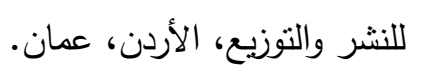

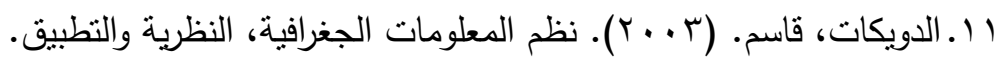

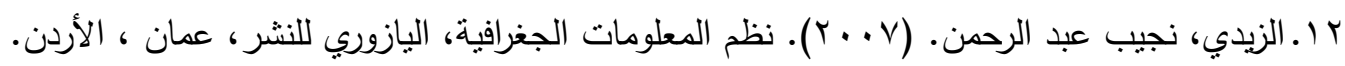

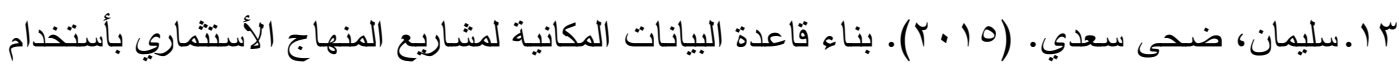
نظم المعلومات الجغرافية ، دبلوم عالي ، الجامعة التكنلوجية.

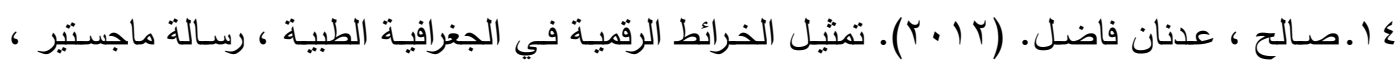

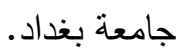

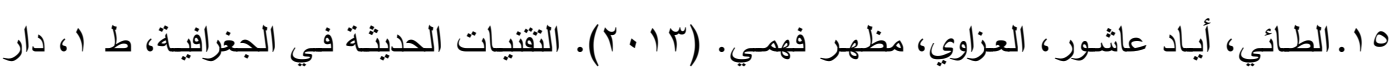
الجنائن للنشر والتوزيع ، عمان، الاردن.

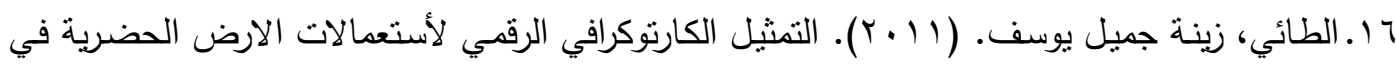

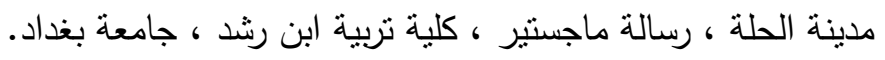

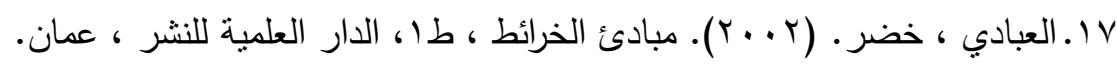

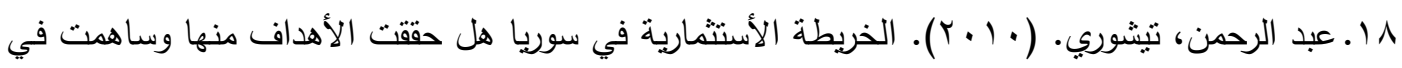

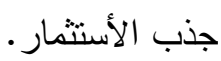




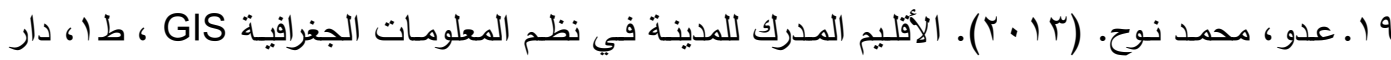

الصفاء للنشر ، عمان.

• r.قربوج، محمد سليم. (د. ت). الخرائط الموضوعية الرقمية ،كلية الاداب والعلوم الإنسانية، جامعة الملك

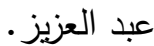

(1) https://books.google.iq.

\section{References translation:}

1. Ahmed, Hanin Hareth. (2015). Preparing and Designing the Tourist Map of Baghdad Using Geographic Information Systems (GIS), Master Thesis, University of Baghdad.

2. Aswad, Falah Shaker. (1988). Cartography, Origin, Development and Principles, Bayt Al-Hikma, University of Baghdad.

3. Baiwi, Marwa Abdul-Razzaq. (2013). Spatial Analysis of Infrastructure Services in Al-Karrada District Using Geographic Information Systems GIS, Master Thesis, University of Baghdad.

4. The Republic of Iraq, Baghdad Investment Commission. (2017). the investment map of Baghdad Governorate.

5. Hajim, Mohamed Youssef. (2010). The Role of GIS Software in Building Data Networks and Digital Maps for Arab Industries and Directing Investment in the Right Place, Seminar on Industrial Information Sector Development in the Arab Countries, Beirut.

6. Hajim, Mohamed Youssef (2016). The Role of GIS Software in Building Data Networks and Digital Maps for Arab Industries and Directing Investment in the Right Place, Seminar on Industrial Information Sector Development in the Arab Countries, Beirut.

7. Hassoun, Hussam Sahib. (2006). The Cartographic Representation of the Population of Iraq According to the 1997 Census, Doctor's Thesis, University of Baghdad.

8. Al-Khuzami, Mohammed Aziz. (2000). The Geographic Information Systems are Based and Applied to Geographers, Edition 2, Al-Marefa facility, Alexandria.

9. Al-Delphi, Haider Abd Radhi. (2011). The Investment Environment and Ways to Upgrade it in Iraq (Wasit Governorate Case Study), Master Thesis, College of Administration and Economics, Wasit University.

10. Al-Dulaimi, Khalaf Hussein. (2010). GIS, Foundations and Applications, 1st edition, Dar Al-Safa for Publishing and Distribution, Jordan, Amman.

11. Al-Dweikat, Qasim. (2003). Geographical Information Systems, Theory and Practice.

12. Al-Zaidi, Najeeb Abdul-Rahman. (2007). Geographic Information Systems, Amman, Jordan, Al-Yazouri Publishing.

13. Suleiman, Dhuha Saadi. (2015). Building a Spatial Database for the Investment Platform Projects Using Geographic Information Systems, Higher Diploma, Technology University.

14. Salih, Adnan Fadhel. (2012). Representing Digital Maps in Medical Geography, Master Thesis, University of Baghdad.

15. Al-Taei, Iyad Ashour, Al-Azzawi, Madher Fahmy. (2013). Modern Technologies in Geography, 1st floor, Dar Al-Janaina for Publishing and Distribution, Amman, Jordan.

16. Al-Tai, Zeina Jamil Yusef. (2011). Digital Cartographic Representation of Urban Land Use in the City of Hilla, Master Thesis, Ibn Rushd College of Education, University of Baghdad. 
17. Al-Abadi, Khader. (2002). Principles of Maps, 1st edition, The Scientific Publishing House, Amman.

18. Abdul-Rahman, Tishuri. (2010). The Investment Map in Syria Have you achieved the goals and contributed to attracting investment.

19. Ado, Muhammad Noah. (2013). the city's perceived region in GIS, 1st edition, Dar Al-Safa Publishing, Amman.

20. Qarbouj, Muhammad Salim. (without date). Digital Topical Maps, College of Arts and Humanities, King Abdulaziz University.

21. https://books.google.iq.

\title{
Designing an investment map and building a geographical database for investment projects in Baghdad Governorate
}

\author{
Asst. Prof. Makki Ghazi Abdul-lateef, PhD \\ Baghdad University \\ College of Education - Ibn Rushd \\ Email: Makki19751975@gmail.com
}

\author{
Wassan Khazal Abdul-Adheem \\ Baghdad University \\ College of Education - Ibn Rushd \\ Email: wasankhazal@gmail.com
}

\begin{abstract}
:
The research dealt with the concept of geographic information systems and the stages of building a geographical database and preparing it for investment projects in Baghdad Governorate, designing and creating a digital investment map and getting acquainted with the number of completed investment projects in the province by type and administrative units and their job classification and indicating their geographical distribution and identifying the factors that contribute to showing this variation as it passes The process of creating the investment map with a set of stages according to the steps of building the map in geographic information systems, as the research shows the geographical and sectoral distribution of investment projects in Baghdad governorate according to Determinants of $\mathrm{Ah}$ affect and are affected by their geographical location be set up.
\end{abstract}

Key words: geographic information systems, database, digital map, completed projects. 